NASA/TM-2016-219129

\title{
Vibrating-Wire, Supercooled Liquid Water Content Sensor Calibration and Characterization Progress
}

Michael C. King

Glenn Research Center, Cleveland, Ohio

John A. Bognar, Daniel Guest, and Fred Bunt

Anasphere, Inc., Bozeman, Montana 


\section{NASA STI Program . . . in Profile}

Since its founding, NASA has been dedicated to the advancement of aeronautics and space science. The NASA Scientific and Technical Information (STI) Program plays a key part in helping NASA maintain this important role.

The NASA STI Program operates under the auspices of the Agency Chief Information Officer. It collects, organizes, provides for archiving, and disseminates NASA's STI. The NASA STI Program provides access to the NASA Technical Report Server-Registered (NTRS Reg) and NASA Technical Report ServerPublic (NTRS) thus providing one of the largest collections of aeronautical and space science STI in the world. Results are published in both non-NASA channels and by NASA in the NASA STI Report Series, which includes the following report types:

- TECHNICAL PUBLICATION. Reports of completed research or a major significant phase of research that present the results of NASA programs and include extensive data or theoretical analysis. Includes compilations of significant scientific and technical data and information deemed to be of continuing reference value. NASA counter-part of peer-reviewed formal professional papers, but has less stringent limitations on manuscript length and extent of graphic presentations.

- TECHNICAL MEMORANDUM. Scientific and technical findings that are preliminary or of specialized interest, e.g., "quick-release" reports, working papers, and bibliographies that contain minimal annotation. Does not contain extensive analysis.
- CONTRACTOR REPORT. Scientific and technical findings by NASA-sponsored contractors and grantees.

- CONFERENCE PUBLICATION. Collected papers from scientific and technical conferences, symposia, seminars, or other meetings sponsored or co-sponsored by NASA.

- SPECIAL PUBLICATION. Scientific, technical, or historical information from NASA programs, projects, and missions, often concerned with subjects having substantial public interest.

- TECHNICAL TRANSLATION. Englishlanguage translations of foreign scientific and technical material pertinent to NASA's mission.

For more information about the NASA STI program, see the following:

- Access the NASA STI program home page at http://www.sti.nasa.gov

- E-mail your question to help@sti.nasa.gov

- $\quad$ Fax your question to the NASA STI Information Desk at 757-864-6500

- Telephone the NASA STI Information Desk at 757-864-9658

- Write to:

NASA STI Program

Mail Stop 148

NASA Langley Research Center Hampton, VA 23681-2199 
NASA/TM—2016-219129

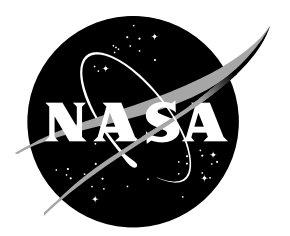

\section{Vibrating-Wire, Supercooled Liquid Water Content Sensor Calibration and Characterization Progress}

Michael C. King

Glenn Research Center, Cleveland, Ohio

John A. Bognar, Daniel Guest, and Fred Bunt

Anasphere, Inc., Bozeman, Montana

Prepared for the

8th Atmospheric and Space Environments Conference

sponsored by the American Institute of Aeronautics and Astronautics

Washington, D.C., June 13-17, 2016

National Aeronautics and

Space Administration

Glenn Research Center

Cleveland, Ohio 44135 
Trade names and trademarks are used in this report for identification only. Their usage does not constitute an official endorsement, either expressed or implied, by the National Aeronautics and Space Administration.

Level of Review: This material has been technically reviewed by technical management.

Available from

NASA STI Program

Mail Stop 148

NASA Langley Research Center

Hampton, VA 23681-2199
National Technical Information Service 5285 Port Royal Road Springfield, VA 22161 703-605-6000

This report is available in electronic form at http://www.sti.nasa.gov/ and http://ntrs.nasa.gov/ 


\title{
Vibrating-Wire, Supercooled Liquid Water Content Sensor Calibration and Characterization Progress
}

\author{
Michael C. King \\ National Aeronautics and Space Administration \\ Glenn Research Center \\ Cleveland, Ohio 44135 \\ John A. Bognar, Daniel Guest, and Fred Bunt \\ Anasphere, Inc. \\ Bozeman, Montana 59718
}

\begin{abstract}
Nomenclature
NASA conducted a winter 2015 field campaign using weather balloons at the NASA Glenn Research Center to generate a validation database for the NASA Icing Remote Sensing System. The weather balloons carried a specialized, disposable, vibrating-wire sensor to determine supercooled liquid water content aloft. Significant progress has been made to calibrate and characterize these sensors. Calibration testing of the vibrating-wire sensors was carried out in a specially developed, low-speed, icing wind tunnel, and the results were analyzed. The sensor ice accretion behavior was also documented and analyzed. Finally, post-campaign evaluation of the balloon soundings revealed a gradual drift in the sensor data with increasing altitude. This behavior was analyzed and a method to correct for the drift in the data was developed.
\end{abstract}

\section{Nomenclature}

$a_{1} \quad$ frequency drift trendline slope

$a_{2} \quad$ frequency drift trendline intercept

$b \quad$ SLWC model coefficient

$c_{2} \quad$ SLWC model wire mass coefficient

$c_{3} \quad$ SLWC model ice mass coefficient

D wire diameter

d diameter

$\varepsilon \quad$ collection efficiency

$f \quad$ frequency

$f_{0} \quad$ natural frequency

$h$ pressure altitude

ILW integrated liquid water

$L_{0} \quad$ total free wire length

$L_{1} \quad$ shielded wire length

$m_{w} \quad$ mass of wire per unit length

$r \quad$ ice density parameter

$\rho \quad$ density

$S \quad$ thickness of blade ice accretion

SLWC supercooled liquid water content

$T$ temperature

$t$ time

$u \quad$ speed 


\section{Introduction}

Inflight icing of aircraft is a hazard to the aviation community. Providing operators with near real-time information of atmospheric icing conditions is a possible means to reduce hazard by operationally minimizing exposure. The NASA Icing Remote Sensing System (NIRSS), which NASA researchers have been developing, can potentially provide this information to pilots and air traffic controllers. However, the NIRSS is still in the development stage, requiring validation from in-situ measurements of icing conditions. Thus, to support NIRSS validation efforts, NASA funded Anasphere, Inc., through the Small Business Innovative Research (SBIR) program, to develop and calibrate weather balloon-borne, supercooled liquid water content (SLWC) sensors that could acquire the necessary in-situ measurements. The sensors Anasphere, Inc. developed are inexpensive, disposable and easily deployable. These characteristics provide both researchers and meteorologists investigating atmospheric icing new opportunity to obtain in-situ measurements of natural icing clouds.

Equipped with the new sensors, NASA researchers conducted a field campaign at the NASA Glenn Research Center (GRC) in Cleveland, Ohio during winter 2015 to develop a NIRSS validation database, and documented the preliminary results in Reference 1. The researchers at NASA coordinated with meteorologists from the National Center for Atmospheric Research (NCAR) in Boulder, Colorado to concurrently operate the NIRSS and release weather balloons during forecast periods of inflight icing conditions over Cleveland to develop the validation database for the system. The weather balloons carried disposable instrument packages, known as radiosondes, vertically through the clouds to acquire and transmit in-situ measurements of atmospheric conditions during ascent to a ground station. The specialized sensors developed by Anasphere, Inc. were attached to these radiosondes. A database of twenty-three weather balloon soundings across twelve different icing events was compiled as a result of the campaign. A means to calibrate and characterize the SLWC sensors was not available at the time of the field campaign and has since been developed.

This paper focuses on the calibration by NASA and Anasphere, Inc. of the SLWC sensors. Significant effort has been made recently to calibrate these sensors, including facility development and experimental testing. The facility, the calibration testing, and the progress towards a thorough sensor calibration are discussed. Additionally, during the calibration testing, a volume of photographic documentation was taken of the ice accretion along the SLWC sensor probe element. Analysis of the ice accretion images are used to further characterize the sensor and refine the equations used to calculate SLWC. Finally, an unexpected behavior observed in the weather balloon SLWC sensor data during the winter 2015 campaign is analyzed, and methods to correct for the behavior are described. The primary objective for this work is to further the understanding of the SLWC sensors, thereby providing improved fidelity to the NIRSS validation database.

\section{Background Information}

The instrument package, shown in Figure 1, released with the weather balloons for the field campaign included the Intermet Systems, Inc. iMet-1-RSBN Radiosonde and the Anasphere, Inc. vibrating-wire, SLWC Sensor. The iMet-1-RSBN is a meteorological radiosonde designed to transmit upper air pressure, temperature, humidity, and GPS data on the $403 \mathrm{MHz}$ meteorological frequency once every second. It is capable of interfacing and transmitting the data acquired by additional third party sensors; this capability was used to obtain the SLWC measurements from the Anasphere, Inc. sensor.

The principle behind the SLWC sensor is the change in natural frequency of a wire due to ice accretion along the wire. The natural frequency of the wire decreases as ice accretes. Profiles of SLWC along the weather balloon flight path can be derived from the time history of the measured wire vibration frequency and ascent speed. Anasphere, Inc. produced a new prototype SLWC sensor through a series of NASA sponsored SBIR contracts starting in 2012, building upon the work published in References 2 to 4. 


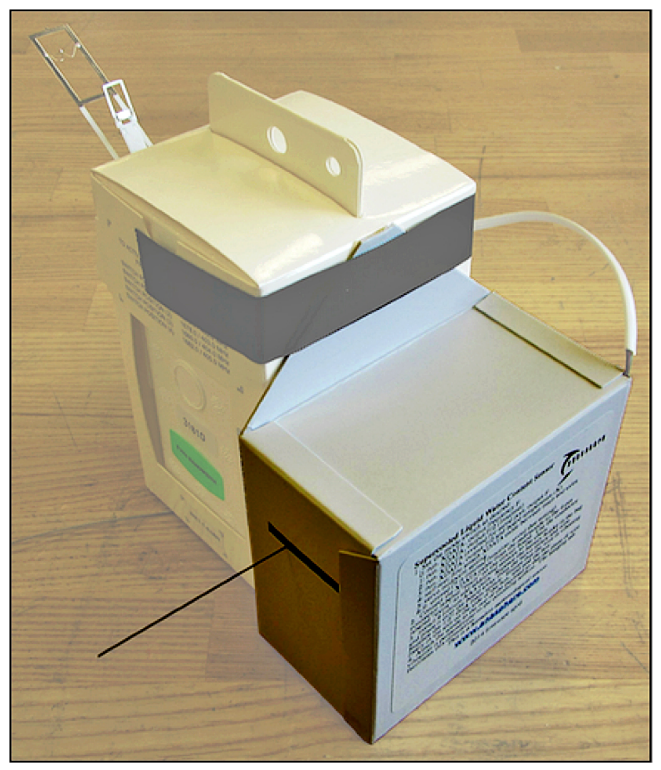

Figure 1.-Instrument package used during the NASA winter 2015 campaign-the SLWC sensor is highlighted in the foreground.

The $0.6 \mathrm{~mm}$ steel wire element, which can be seen extending from the slot in the highlighted carton board enclosure in Figure 1, is periodically "plucked" using a servomotor with a magnet attached to a short support. A thin film piezoelectric sensor, which is inserted between two silicone rubber squares along with the base of the wire, measures the wire vibration frequency. The natural frequency is nominally determined every $3 \mathrm{sec}$ through an Anasphere, Inc. proprietary signal processing method. The sensor shown in Figure 1 is the third generation of the Anasphere, Inc. SLWC sensor. Further information on the first and second generation sensors is available in References 5 and 6, respectively.

\section{Calibration}

\section{Facility Development}

A low speed icing tunnel was developed by Anasphere, Inc. for calibration testing of the SLWC sensors as a part of the SBIR contract. The facility is a closed circuit, fan driven, icing tunnel capable of achieving steady airspeeds in its 30 by $30 \mathrm{~cm}$ test section around $5 \mathrm{~m} / \mathrm{s}$, the nominal ascent rate of the winter 2015 campaign weather balloons. The tunnel heat exchanger is capable of cooling and maintaining the air to subfreezing temperatures. A single Spraying Systems Co. 1/4J-SS air-atomizing nozzle is used to create the supercooled cloud. The nozzle air and water pressures are independently controlled, and the water supply was chilled to ensure supercooling. Figure 2 shows a side view of the tunnel test section with SLWC sensor enclosure and Phase Doppler Interferometer (PDI) used during the calibration testing.

\section{Calibration Testing}

The testing was carried out in two phases. The first phase of testing utilized the SLWC sensor and an Artium Technologies, Inc. Phase Doppler Interferometer, model PDI 300, which measured the particle size and speed distributions. The PDI measurements were non-intrusive, and the sample volume was situated at the centerline of test section, approximately $20 \mathrm{~cm}$ upstream of the SLWC sensor. 


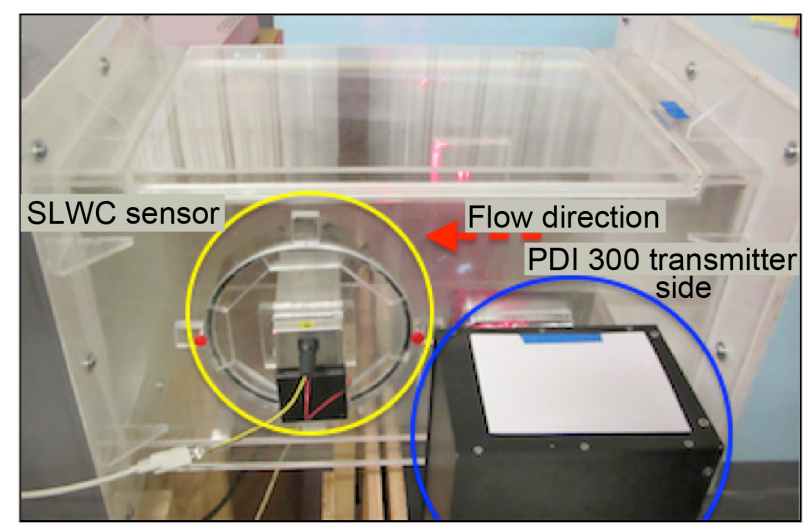

Figure 2.-Low-speed icing tunnel test section.

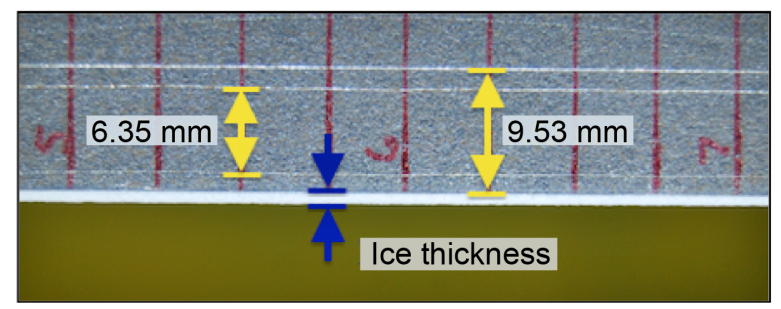

Figure 3.-Reduced resolution icing blade image.

The vibration plane of the SLWC sensor wire was orthogonal to the flow direction, and the mid-point of the wire was positioned at the centerline of the test section. Once the tunnel temperature stabilized, the nozzle water and air pressures were varied for each spray to achieve the desired liquid water content. The air temperature, the particle size and speed distributions, and the SLWC sensor frequency were acquired for a "cloud on" duration of at least $60 \mathrm{sec}$ for each case.

The second phase of testing focused on obtaining independent measurements of the SLWC for the same conditions as the first phase of testing. Since there were concerns taking these measurements using hotwire instruments, such as instrument operability, measurement quality, and additional heat load on the facility, an ice accretion method was used. A $0.64 \mathrm{~mm}$ thick icing blade that spanned the horizontal length of the test section, thereby allowing the blade to be supported on both sides, was used to measure the SLWC. The spray times were varied for each condition to achieve an approximately $0.6 \mathrm{~mm}$ thick ice accretion, which ensured that accretion would have minimal effect on the collection efficiency and avoid shedding. The ice thickness was photographed at marked locations along the span of the blade, as indicated in Figure 3.

\section{Calibration Testing Data Reduction}

In order to obtain the SLWC values from the sensor, the frequency profiles were smoothed with a robust local regression using weighted linear least squares and a second degree polynomial (LOESS) routine available in MATLAB (The Mathworks, Inc., Natick, MA) as described in Reference 6. Figure 4 shows the smoothed experimental frequency data from the SLWC sensor for four of the ten calibration cases for clarity. The frequency time derivative is the primary term in the calculation of SLWC from the vibrating-wire sensors. The trends for each case are linear, and all have coefficient of determination values, $R^{2}$, greater than 0.996 , indicating good correlation. A generalized central differencing method is typically used to determine the incremental $d f / d t$ every three seconds for a weather balloon sounding, but based on the high degree of correlation, the trend $d f / d t$ values were used as constants to calculate the SLWC for the sensor. 


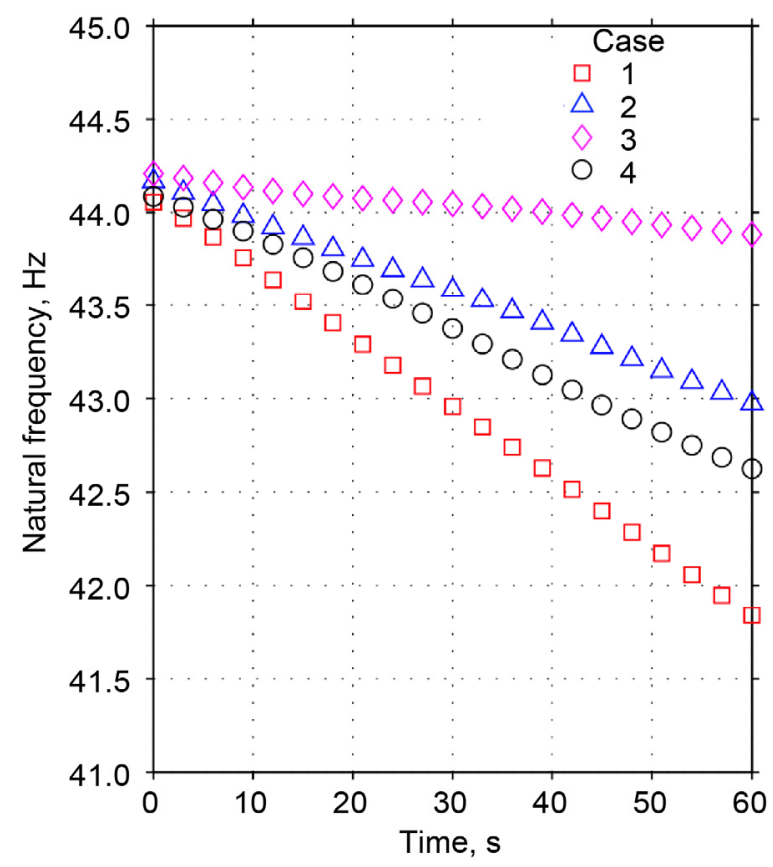

Figure 4.-Select SLWC sensor frequency profiles.

The sensor SLWC values were then calculated using Equation (1). In Equation (1), the terms $f, f_{0}, t$, $D$, and $u$ are the wire vibration frequency, the clean wire natural vibration frequency, the time, the wire diameter, and the airspeed, respectively. The term $b$ is a coefficient defined by Equations (2) to (4), where generalized forms of Equations (3) and (4) were derived and published in Reference 6. The term $m_{w}$ is the mass of the steel wire per unit length, $2.2 \times 10^{-3} \mathrm{~kg} / \mathrm{m}$. The terms $L_{0}, 0.94 \mathrm{~mm}$, and $L_{1}, 0.35 \mathrm{~mm}$, are the total free length and the shielded length of the wire, respectively. The mean particle speed, $u_{p}$, measured by the PDI was assumed to be equivalent to the airspeed, $u$, in Equation (1). Table 1 shows the calculated results. As can be seen in the frequency time derivative values in Table 1, increasingly negative $d f / d t$ values correlate directly to increasing SLWC values for the sensor.

$$
\begin{aligned}
\text { SLWC } & =-\frac{2 b f_{0}^{2}}{\varepsilon D u f^{3}} \frac{d f}{d t} \\
b & =\frac{c_{2}}{c_{3}} m_{w} \\
c_{2} & =\left(\frac{3 \pi-8}{2 \pi}\right) \\
c_{3}=\frac{1}{2 \pi}\left[8 \sin \left(\frac{\pi L_{1}}{2 L_{0}}\right)-\right. & \left.\sin \left(\frac{\pi L_{1}}{L_{0}}\right)+3 \pi\left(1-\frac{L_{1}}{L_{0}}\right)-8\right]
\end{aligned}
$$


TABLE 1.-CALIBRATION TEST MEASUREMENTS AND RESULTS

\begin{tabular}{|c|c|c|c|c|c|c|c|c|c|c|c|}
\hline & \multicolumn{5}{|c|}{ SLWC sensor and PDI testing } & \multicolumn{6}{|c|}{ Blade testing } \\
\hline Case & $\begin{array}{l}d_{v 0.50} \\
(\mu \mathrm{m})\end{array}$ & $\begin{array}{c}T \\
\left({ }^{\circ} \mathrm{C}\right) \\
\end{array}$ & $\begin{array}{c}u_{p}{ }^{*} \\
(\mathrm{~m} / \mathrm{s}) \\
\end{array}$ & $\begin{array}{c}d f / d t \\
\left(\sec ^{-2} \times 10^{2}\right)\end{array}$ & $\begin{array}{l}\begin{array}{l}\text { SLWC } \\
\left(\mathrm{g} / \mathrm{m}^{3}\right)\end{array} \\
\end{array}$ & $\begin{array}{c}t \\
(\mathrm{sec}) \\
\end{array}$ & $\begin{array}{c}S \\
(\mathrm{~mm})\end{array}$ & $\begin{array}{c}T \\
\left({ }^{\circ} \mathrm{C}\right) \\
\end{array}$ & $\begin{array}{c}r \\
\left(\mathrm{~m}^{2} / \mathrm{s}^{\circ} \mathrm{C}\right) \\
\end{array}$ & $\begin{array}{c}\rho_{\mathrm{i}} \\
\left(\mathrm{kg} / \mathrm{m}^{3}\right)\end{array}$ & $\begin{array}{c}\text { SLWC } \\
\left(\mathrm{g} / \mathrm{m}^{3}\right)\end{array}$ \\
\hline \multicolumn{12}{|c|}{$\mathrm{P}_{\mathrm{H} 2 \mathrm{O}}=10$ psig series } \\
\hline 1 & 35 & -10 & 5.7 & -3.79 & 1.15 & 105 & 0.75 & -14 & 6.5 & 455 & 0.71 \\
\hline \multicolumn{12}{|c|}{$\mathrm{P}_{\mathrm{H} 2 \mathrm{O}}=20$ psig series } \\
\hline 2 & 32 & -10 & 5.5 & -1.96 & 0.74 & 80 & 0.78 & -14 & 5.9 & 430 & 0.92 \\
\hline 3 & 30 & -11 & 5.1 & -1.90 & 0.64 & 120 & 0.62 & -14 & 5.6 & 400 & 0.46 \\
\hline 4 & 27 & -10 & 5.2 & -1.04 & 0.35 & 165 & 0.71 & -15 & 4.6 & 350 & 0.34 \\
\hline 5 & 24 & -10 & 5.0 & -0.52 & 0.19 & 270 & 0.51 & -14 & 4.3 & 330 & 0.15 \\
\hline \multicolumn{12}{|c|}{$\mathrm{P}_{\mathrm{H} 2 \mathrm{O}}=30$ psig series } \\
\hline 6 & 35 & -10 & 5.8 & -4.75 & 1.39 & 60 & 0.74 & -13 & 6.6 & 460 & 1.24 \\
\hline 7 & 30 & -10 & 4.6 & -2.19 & 0.79 & 65 & 0.69 & -14 & 5.4 & 400 & 0.94 \\
\hline 8 & 29 & -9 & 5.3 & -1.51 & 0.49 & 70 & 0.71 & -14 & 5.3 & 390 & 0.89 \\
\hline 9 & 26 & -10 & 4.9 & -1.03 & 0.37 & 75 & 0.68 & -14 & 4.7 & 360 & 0.75 \\
\hline 10 & 23 & -10 & 4.9 & -0.84 & 0.29 & 80 & 0.61 & -14 & 4.2 & 330 & 0.59 \\
\hline
\end{tabular}

${ }^{a}$ Mean Particle Speed assumed to be tunnel test section speed

${ }^{b}$ Vibrating Wire Sensor SLWC values

'Blade SLWC values

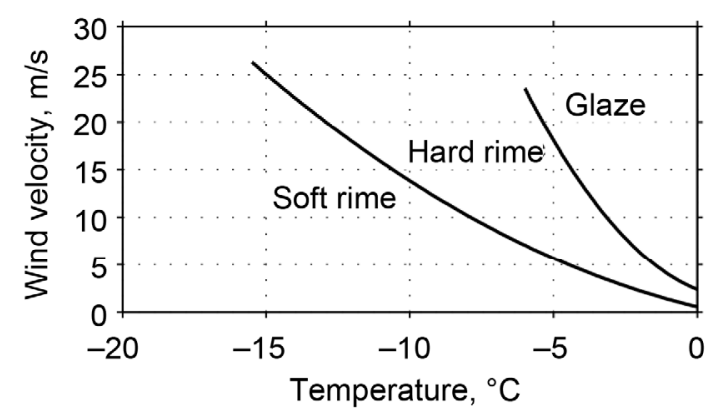

Figure 5.--Ice accretion formation regimes (reproduced from Ref. 8).

The blade SLWC values shown in Table 1 were calculated using the blade equation, Equation (5), described in Reference 7. The terms $\rho_{i}, S, \varepsilon, u$ and $t$ are the ice density, the ice accretion thickness, the collection efficiency, the airspeed, and the spray duration, respectively. The precise ice accretion thickness, $S$, for each case was determined from the images using the scale on the blade shown in Figure 3. Reference 8 provides an empirical relation, Equation (6), which can be used to estimate soft rime ice density for values of $r$, the ice density parameter defined by Equation (7), between 0.8 and 10. A soft rime ice accretion, which was previously observed in Reference 4 for similar vibrating-wire sensors, was observed during testing. Figure 5 shows ranges of air temperatures and wind speeds in which different ice accretions have been observed as noted in Reference 9. The calibration test conditions fall well within the soft rime region defined in Figure 5. The terms $d_{v 0.50}$ and $T_{s}$ are the median volumetric diameter (MVD) and the blade-ice surface temperature, respectively. The blade-ice surface temperature was assumed to be equivalent to the tunnel air temperature in this analysis.

$$
\begin{gathered}
\text { SLWC }=\frac{\rho i S}{\varepsilon u t} \\
\rho_{i}=110 r^{0.76} \\
r=-5 \times 10^{5} \frac{d_{v 0.50} u_{p}}{T_{S}}
\end{gathered}
$$




\section{Sensor Calibration Results}

Figure 6 shows the calculated SLWC profiles for each case over a $60 \mathrm{sec}$ period. The calculated SLWC profiles for all cases rise to varying degrees, between 3 and 17 percent, over a 1 min duration. The rise in the calculated SLWC is proportional to the indicated SLWC. This effect may be of due to the general form of Equation (1), where the cubed frequency term, $f$, in the denominator decreases with continued exposure to the supercooled cloud, thus increasing the calculated SLWC. Other effects such as cloud recirculation in the facility may also be contributing factors, which were not investigated for these tests. However, the linearity of the frequency profiles suggest that SLWC in the test section remained fairly constant during any given case. If the effect is primarily a response to the form of Equation (1), the results suggest an upper engineering limit to the sensor equations somewhere between $0.75 \mathrm{~g} / \mathrm{m}^{3}$ and 1 $\mathrm{g} / \mathrm{m}^{3}$. It should be noted that sustained exposure to liquid water contents of $0.75 \mathrm{~g} / \mathrm{m}^{3}$ or greater for over a minute represents a significant and particularly thick supercooled cloud layer, which were not typically encountered by the weather balloons released during the 2015 field campaign into winter stratiform clouds.

Finally, Figure 7 shows the comparison between the calculated sensor and blade SLWC values. The correlation between the two measurements is promising, as Figure 7 demonstrates that the blade and sensor values tend to agree to well within \pm 25 percent in several cases, as indicated by the dashed lines. Case 3 , the point from the 20 psig water pressure series outside the \pm 25 percent lines, falls within \pm 30 percent, while the points from the remaining cases are well within \pm 50 percent. Additional testing is required to increase the available data set and formulate a more complete understanding of the SLWC sensor performance.

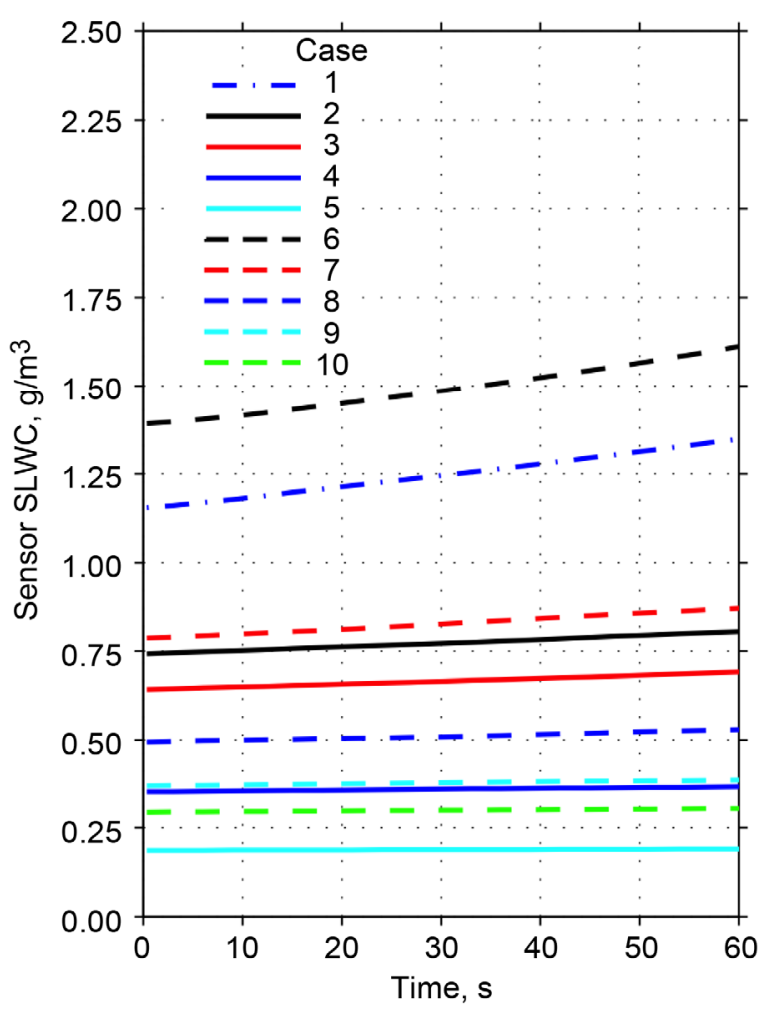

Figure 6.-Sensor SLWC profiles showing gradual increase in calculated SLWC proportional to the indicated SLWC.

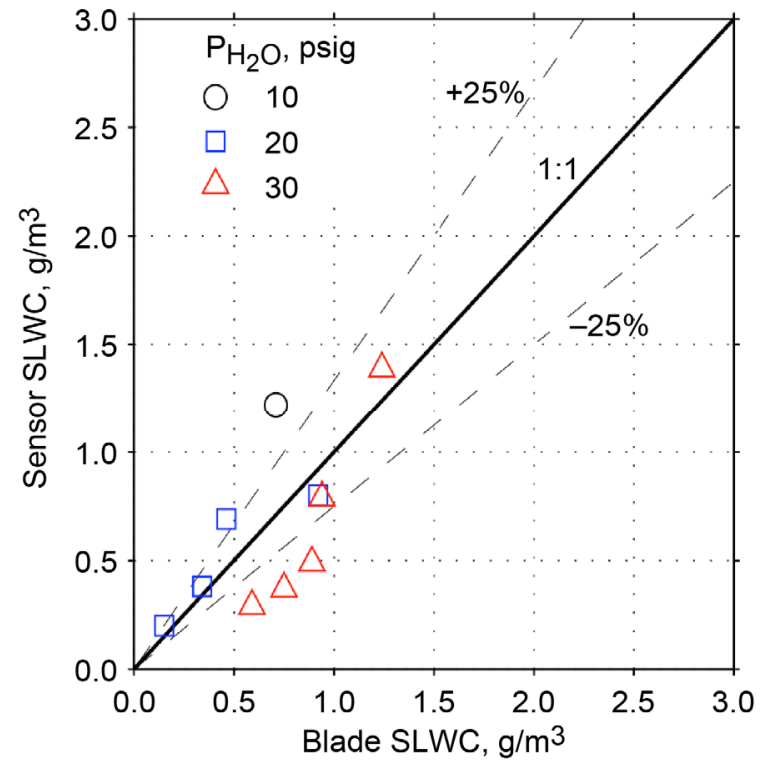

Figure 7.-Sensor and blade SLWC comparison. 


\section{Ice Accretion Analysis}

The tunnel testing presented the opportunity to observe the character of the ice accretion upon the sensing element, and to obtain images such as those shown in Figure 8. The distance between the caliper tips is $30 \mathrm{~mm}$ in both images. Both images in Figure 8 show a distinct shadow zone at the base of the element, indicating the extent of the particle boundary layer, which has not been previously documented. The length of wire without ice accretion, $L_{1}$, is a parameter that is used to calculate the sensor SLWC, and this information allowed researchers to improve the fidelity of the model. While the initial impressions of the researchers were that the existence of this shadow zone would have a significant effect on the results, an analysis, as described below, demonstrated that the effect in the calculation is negligible.

The assumed ice accretion along the wire sensing element used in Reference 2 to 4, and Reference 6 is shown in Figure 9. The total effective length of the wire, $L_{0}$, has been assumed to be the length from the wire tip to the point the wire is "rigidly" clamped, the edge of the two silicone rubber squares previously mentioned. The term for the shielded wire length, $L_{1}$, was previously assumed to be the length from the edge of silicon rubber squares to the outside edge of the sensor enclosure. The difference between these two lengths sets the exposed length of the wire used in Equations (1), (2), and (4). For the Anasphere, Inc. SLWC Sensor, the values used in all previous works for $L_{0}$ and $L_{1}$ were 94 and $25 \mathrm{~mm}$, respectively. Based on the image data, there is a shadow zone along the wire of approximately $10 \mathrm{~mm}$, within which ice did not accrete during testing.
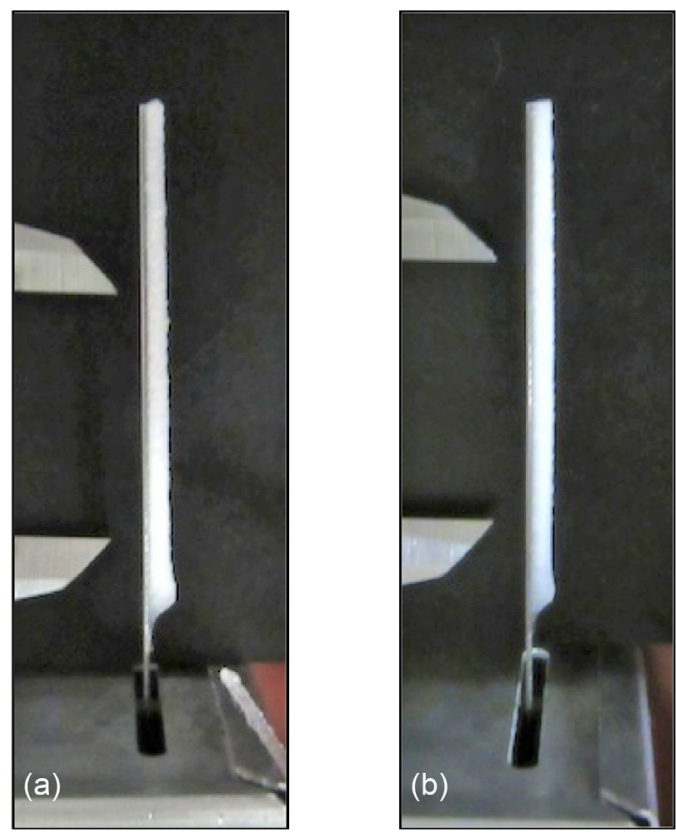

Figure 8.-Wire ice accretion from tunnel testing showing shadow zone.

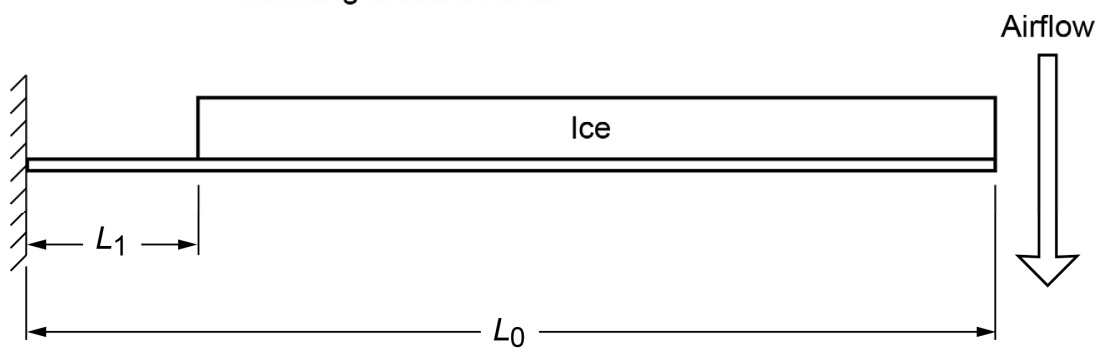

Figure 9.-Illustration of ice accretion upon the wire (reproduced from Ref. 4). 
The increase of $L_{1}$ from 25 to $35 \mathrm{~mm}$ was examined for cases 1 through 10, and the effect was determined to be insignificant. The SLWC increased by a consistent 0.75 percent in every case. The insensitivity of the calculated SLWC is a function of the model coefficient, $b$, defined in Equation (2), which only increases by less than a few percent for values of $L_{1}$ approaching 50 percent of the total wire length, $L_{0}$. While the effect in the SLWC calculation is negligible, the approximately 15 percent decrease in the effective exposed wire affects the amount of ice mass accreting on the wire, and thus affects the frequency depression. Note that all sensor SLWC values reported in this document were calculated using the corrected $L_{1}$ value. Additionally, the calibration testing did not investigate the existence of the shadow zone at varying sensor orientations to the freestream, which would be expected during a weather balloon sounding.

\section{Sensor Data Drift}

\section{Data Analysis}

The wire vibration frequency profiles for several of the soundings from the winter 2015 campaign demonstrate an upwards drift in the frequency with increasing altitude. Figure 10 shows two examples of this behavior. Figure 10(a) shows the typical sensor response to an encounter with significant levels of SLWC, marked by the frequency depression and subsequent gradual recovery upon exiting icing conditions. Figure 10(b) shows a null case from a clear-skies day, where the weather balloon did not encounter measurable quantities of SLWC. The gradual increase, or drift, in the frequency profiles is observable in both of figures. The drift is linear when plotted on a logarithmic pressure scale, and does not appear to be affected by the presence of icing conditions as shown in Figure 10(a).

Thermal effects in the sensor materials caused by decreasing temperature were hypothesized to be the reason for the frequency drift. The primary suspect sources include (1) increased modulus of elasticity of the silicone rubber clamping structure, reducing the effective length of the wire by decreasing the clamp's structural pliability, and (2) increasing modulus of elasticity of the wire, thus stiffening the wire. Both effects would lead to increases in the natural frequency of the wire. There is influence of temperature on the thin film piezoelectric sensor, but this effect is in the amplitude of the voltage signal, not the median frequency. Thus, it was not investigated in the following analysis.
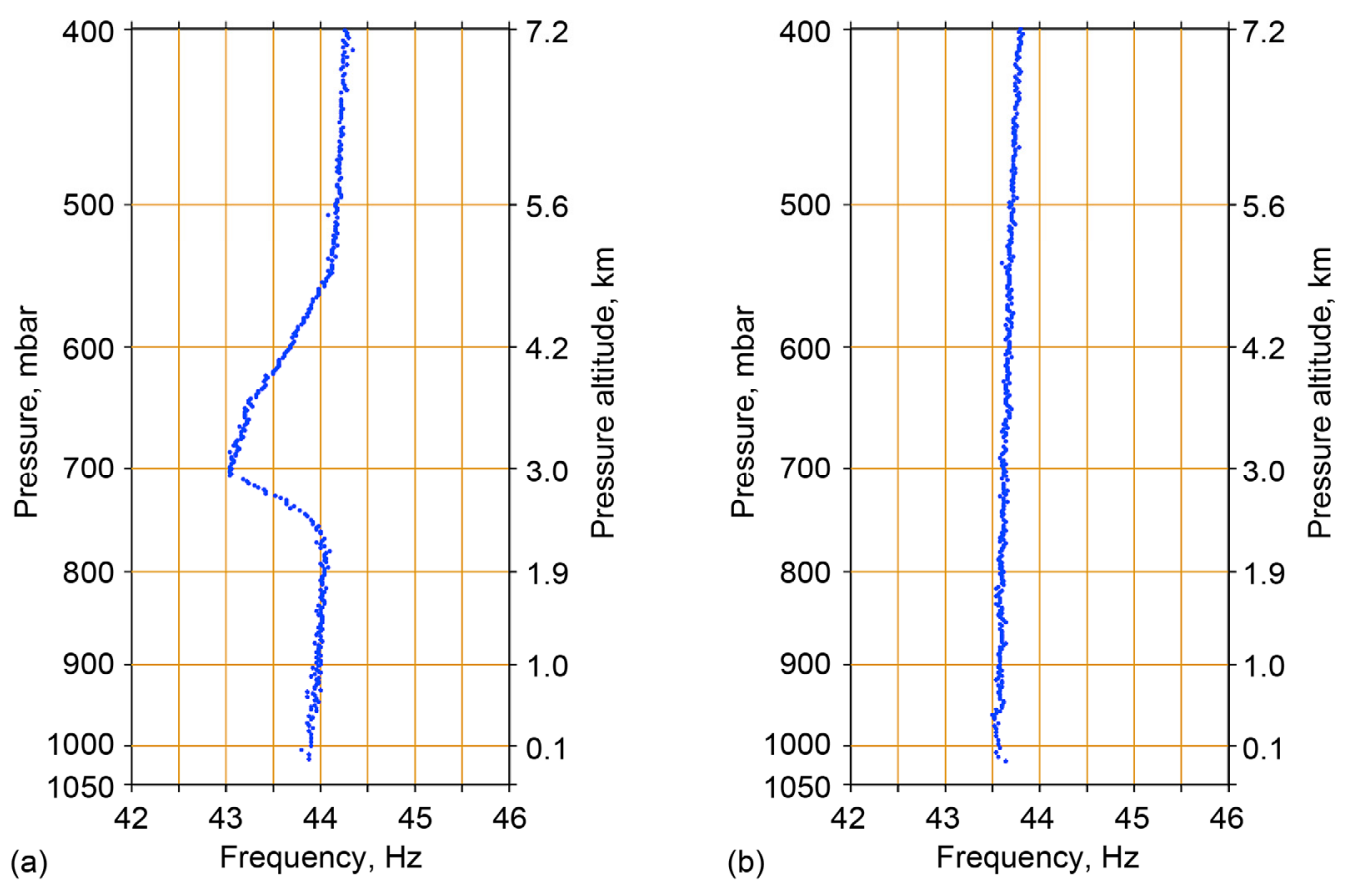

Figure 10.-Sensor and blade SLWC comparison. 

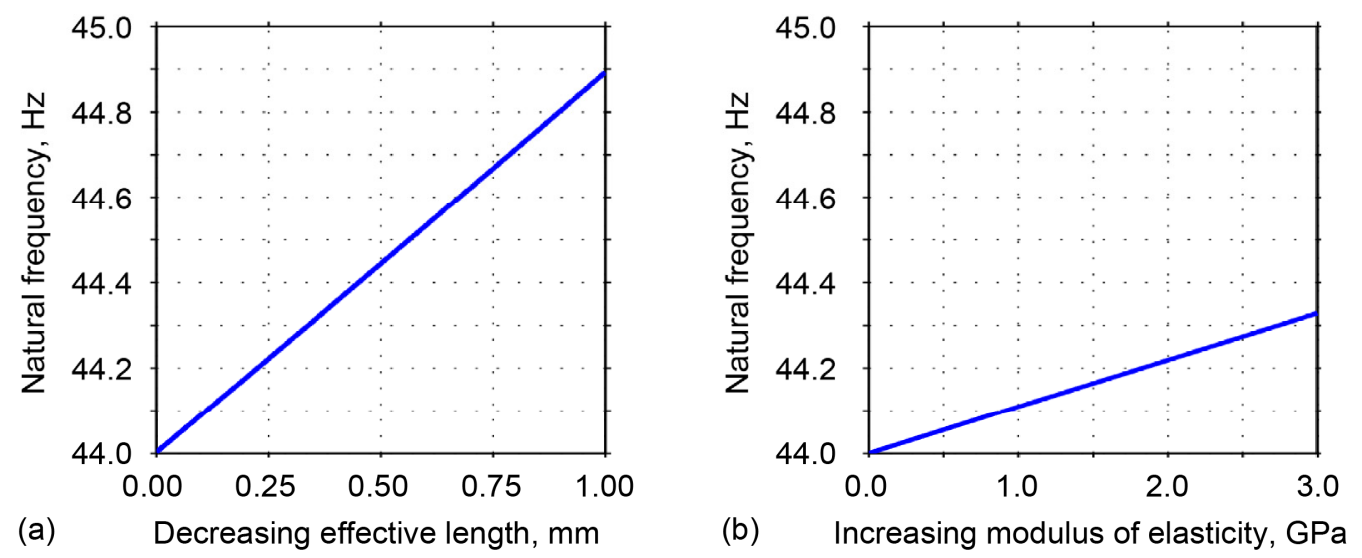

Figure 11.-Relative comparison of thermal material and structural affects on SLWC sensor.

Figure 11 shows the relative effects comparison between decreasing effective wire length and increasing wire stiffness. The left plot shows that decreasing the effective length marginally by $1 \mathrm{~mm}$, about 1 percent, can increase the natural frequency by almost $1 \mathrm{~Hz}$. This is similar in magnitude to the frequency depression observed during moderate icing conditions. The right plot shows the effect of the wire stiffening. The modulus of elasticity for 1080 Carbon Steel is approximately $204 \mathrm{GPa}$ at $0{ }^{\circ} \mathrm{C}$, and increases by approximately $3 \mathrm{GPa}$, about 1 percent, from 0 to $-50{ }^{\circ} \mathrm{C}$ (Ref. 10). This can lead to an increase in the wire natural frequency of $0.3 \mathrm{~Hz}$. The magnitude of each of these effects suggests that both are potentially contributing factors to the frequency drift behavior.

\section{Laboratory Testing and Analysis}

A SLWC sensor was tested in a controlled laboratory environment to better understand this behavior. A small slit was placed in the side of one of the silicone rubber squares, and a thin thermocouple was inserted with thermal compound to approximately measure the temperature of the silicone rubber square during testing. The sensor was placed in a freezer with controllable temperature, and the temperature and frequency were recorded over a period of approximately $30 \mathrm{~min}$, until the measured temperature reached the coldest setting for the freezer, $-15^{\circ} \mathrm{C}$. There was no measurable difference between the SLWC sensor natural frequency during testing at room temperature before and after modification to accommodate the thermocouple.

Figure 12 shows the frequency drift profiles for several soundings from the winter 2015 campaign and the laboratory test. Three of the profiles have frequency depressions, approximately between $0{ }^{\circ} \mathrm{C}$ and $-10{ }^{\circ} \mathrm{C}$, which are due to the ice accretion upon the wire. The data clustering near $-60{ }^{\circ} \mathrm{C}$ for some cases is due to the weather balloons reaching the isothermal layer near the tropopause. Each SLWC sensor is unique - the clean-wire, natural frequency varies for each sensor. However, the slopes of the profiles are relatively similar. The profile from laboratory testing is generally similar in trend to the profiles from the balloon soundings, which confirms the hypothesis that the drift is due to thermal effects. 


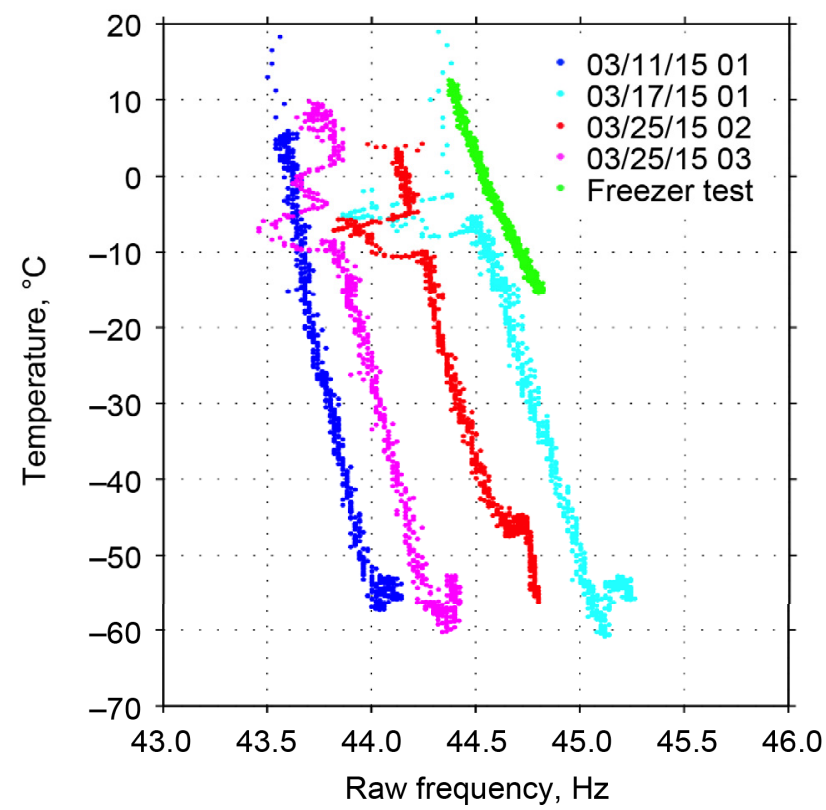

Figure 12.-Frequency data with decreasing temperature for several campaign balloon soundings and laboratory testing.

\section{Correcting Data}

A method to correct the winter 2015 campaign data was developed and applied to the soundings with the apparent drift behavior. The linearity of the profiles when plotted on a logarithmic scale is apparent in Figure 10. A trend was developed for each sounding, given by Equation (8), and the soundings were corrected by removing the difference between trend and the natural frequency from the frequency profile. The terms $h, a_{1}$, and $a_{2}$ in Equation (10) are the pressure altitude, the trendline slope, and the trendline pressure altitude axis intercept, respectively.

$$
h=a_{1} \log _{10} f+a_{2}
$$

Figure 13 shows the correction applied to the 03/20/2015-01 balloon sounding. The left hand plot shows the temperature, shown in red, and dewpoint, shown in blue, profiles on a Skew-T, Log-P chart. The profiles indicate the presence of cloud where the dewpoint depresses to coincide with the temperature. The center plot shows the corrected and uncorrected frequency profiles and the frequency drift trendline. Finally, the right plot shows the calculated SLWC profiles based on the corrected and uncorrected frequency profiles, where the SLWC profile was calculated using Equation (1).

The trendline captures the frequency drift well in Figure 13, and the difference between the corrected and uncorrected frequency profiles is greater at the higher altitudes. The difference between the two SLWC profiles appears marginal, leading to only a 3 percent increase in the maximum SLWC, but a 20 percent increase in the integrated liquid water (ILW), from 0.25 to $0.3 \mathrm{~mm}$, given by Equation (9). The term $\rho$ is the density of liquid water in Equation (9).

$$
\mathrm{ILW}=\frac{1}{\rho\left(\mathrm{H}_{2} \mathrm{O}\right)_{\text {liq }}} \int_{t_{0}}^{t} \operatorname{SLWC} u d t
$$

This method will allow researchers to correct the weather balloon profiles from the winter 2015 campaign for the observed frequency drift behavior for the NIRSS validation database, leading to an improved evaluation the NIRSS algorithms. 

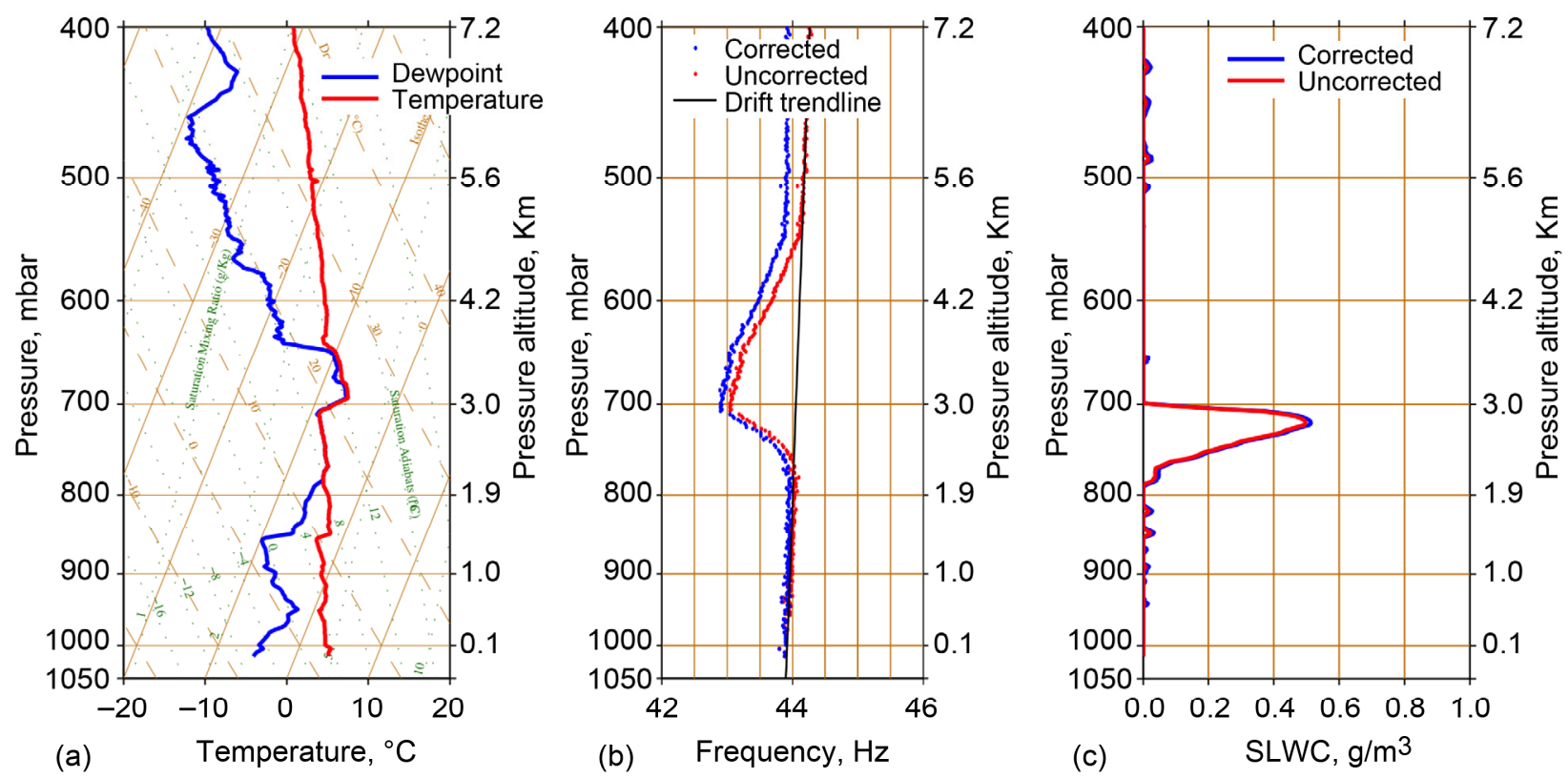

Figure 13.-03/20/2015-01 Sounding profile including the temperature and dewpoint profile on (a) Skew-T, Log-P chart. (b) Frequency profiles. (c) Resulting SLWC profiles.

\section{Summary and Conclusions}

Significant progress has been made in the calibration and characterization of the balloon-borne, vibrating-wire, SLWC sensors. A specialized facility was developed, calibration testing was conducted, and test results were analyzed for these inexpensive, disposable sensors. The preliminary test results are very encouraging. There is reasonably good agreement between the sensor and blade SLWC values in the majority of the cases. However, an expanded calibration database is required to develop more in depth conclusions on the accuracy of the sensors. Additionally, preliminary results from testing suggest that calculations may require modification to handle larger mass formations on the sensing element, which are associated with lower frequencies. The gradual increase in calculated SLWC without a corresponding decrease in the frequency time derivative support this conclusion.

Photographic documentation was also taken, allowing for an improved understanding of the ice accretion along the SLWC probe element. The existence of a shadow zone was confirmed and quantified. The effect of the shadow zone on the SLWC calculation was found to be negligible through analysis. However, the existence of the shadow zone will retard the frequency depression by limiting ice accretion.

Finally, possible causes for the frequency drift in the winter 2015 weather balloon campaign were investigated, and a method to correct the data was developed and presented. This method will be useful to researchers until the Anasphere, Inc. SLWC Sensor is developed further to address the frequency drift behavior.

The results of this work have furthered the understanding of the SLWC sensors and improved the fidelity of the NIRSS validation database. These sensors have great promise and potential in the field of atmospheric icing research - the sensors are inexpensive, disposable and easily deployable, which affords both researchers and meteorologists new opportunities to obtain in-situ natural icing cloud measurements. 


\section{References}

1. Serke, D., et al., "Analysis of 2015 Winter Inflight Icing Studies With Ground-Based Remote Sensing Systems Compared to In-situ SLW-Sondes," NASA/TM-2016-219130, 2016.

2. Hill, G.E. and Woffinden, D., "A Balloonborne Instrument for the Measurement of Vertical Profiles of Supercooled Liquid Water Concentration," Journal of Applied Meteorology, vol. 19, 1980, pp. 1285-1292.

3. Hill, G.E., "Laboratory Calibration of a Vibrating Wire Device for Measuring Concentrations of Supercooled Liquid Water," Journal of Atmospheric and Oceanic Technology, vol. 6, 1989, pp. 961-970.

4. Hill, G.E., "Analysis of Supercooled Liquid Water Measurements Using Microwave Radiometer and Vibrating Wire Devices," Journal of Atmospheric and Oceanic Technology, vol. 11, 1994, pp. 1242-1252.

5. Serke, D., et al., "Supercooled Liquid Water Content Profiling Case Studies With a New Vibrating Wire Sonde Compared to a Ground-based Microwave Radiometer," Atmospheric Research, vol. 149, 2014, pp. 77-87.

6. King, M.C., "Supercooled Liquid Water Content Instrument Analysis and winter 2014 Data with Comparisons to the NASA Icing Remote Sensing System and Pilot Reports," NASA/TM-2016219092, 2016.

7. Ide, R.F. and Sheldon, D.W., "2006 Icing Cloud Calibration of the NASA Glenn Icing Research Tunnel," NASA/TM-2008-215177, 2008.

8. Macklin, W.C., "The Density and Structure of Ice Formed by Accretion," Quarterly Journal of the Royal Meteorological Society, vol. 88, 1962, pp. 30-50.

9. Kiessling, F., Nefzger, P., and Kaintzyk, U., G.C. (ed.), Overhead Power Lines: Planning, Design, Construction, Springer-Verlag Berlin Heidelberg, New York, 2003, p. 167.

10. ASME B31.1a-2008: Addenda to ASME B31.1-2007: Power Piping, American Society of Mechanical Engineers, New York, NY, 2008. 


